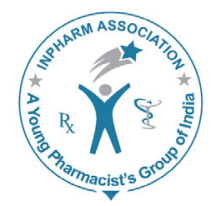

\title{
Assessment of the Photoprotective Activity of Lippia Species from Brazil and Their use as Single UV Filters in Sunscreens
}

\author{
Karla Mara Gonçalves ${ }^{1}$, Hudson Caetano Polonini', Lyderson Facio Viccini ${ }^{2}$, \\ Marcos Antônio Fernandes Brandão ${ }^{1}$ and Nádia Rezende Barbosa Raposo ${ }^{1 *}$ \\ ${ }^{1}$ NUPICS-Núcleo de Pesquisa e Inovação em Ciências da Saúde, Federal University of Juiz de Fora \\ (UFJF), Minas Gerais, Brazil.
}

${ }^{2}$ Instituto de Ciências Biológicas, Departamento de Biologia, Laboratório de Genética, Federal University of Juiz de Fora (UFJF), Minas Gerais, Brazil.

\begin{abstract}
Objective: The present in vitro study aimed to evaluate the photoprotective activity of four plant species from Brazil. Material and Methods: Plants (Lippia brasiliensis, L. pseudothea, L. rotundifolia and L. rubella) were collected in Minas Gerais state, Brazil, and ethanolic extracts were obtained. These were incorporated in neutral lotions and their SPF, UVAPF, UVA/ UVB Ratio and Critical Wavelength were determined by diffuse transmittance spectroscopy. Results: The best results were obtained with $L$. brasiliensis. It was demonstrated that this species generated an estimated in vitro SPF of $9 \pm 1.0$, and an effective UVAPF of $8 \pm 0.7$, at $15 \%$ in a neutral lotion. Conclusion: Broad spectrum sunscreens were obtained when all of four species were used as single UV filter in the sunscreens formulations, although L. brasiliensis presented the best UVA/UVB balance.
\end{abstract}

Key words: Diffuse transmittance, Lippia, Natural products, Plant extracts, Sunscreens.

\section{INTRODUCTION}

Sunscreens are worldwide known cosmeceuticals used to protect epidermis and dermis from photo degradation and photo oxidation triggered by solar ultraviolet (UV) radiations. ${ }^{1}$ The class of cosmeceuticals includes products formulated with pharmaceutical and active type of ingredients, in which phytocosmetics made with natural

\begin{tabular}{|c|c|}
\hline \multicolumn{2}{|c|}{ Access this article online } \\
\hline Journal Sponsor & \multirow[b]{2}{*}{$\begin{array}{l}\text { Website: } \\
\text { www.jyoungpharm.org }\end{array}$} \\
\hline & \\
\hline www.phe & $\begin{array}{l}\text { DOI: } \\
\text { 10.5530/jyp.2015.4.11 }\end{array}$ \\
\hline
\end{tabular}

ingredients from plants represent a huge focus on products research and marketing. ${ }^{2}$

In spite of the stimulation of the studies involving medicinal plants by World Health Organization (WHO), the clinical efficacy and safe use of many of these medicines are still poor understood, ${ }^{3}$ reason why studies on this field are always encouraged.

It is well known the outstanding species richness found in the Neotropics. Comprising around 90,000-110,000 species of seed plants, the Neotropicsalone harbours about $37 \%$ of the world's species. ${ }^{4}$ On the other hand, only a small fraction of the immense diversity of plant metabolism has

*Address for correspondence:

Dr Nádia Rezende Barbosa Raposo, NUPICS-Núcleo de Pesquisa e Inovação em Ciências da Saúde, Federal University of Juiz de Fora (UFJF), Minas Gerais, Brazil.E-mail: nadiacritt@gmail.com 

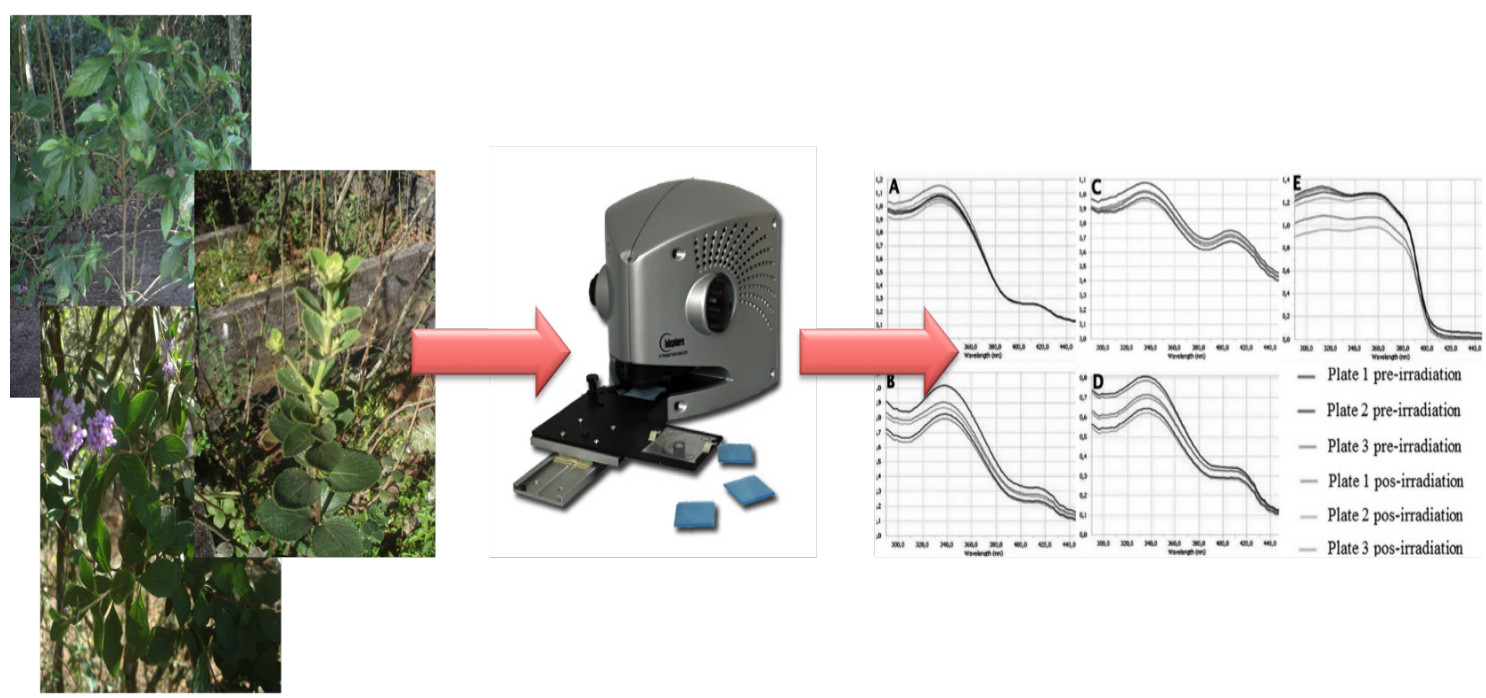

Graphical Abstract

been explored for the production of new medicines and other products important to human well-being. ${ }^{5}$ As part of the Neotropics, Brazil possibly harbours the Earth's richest flora, at least 50,000 species or one-sixth of the planetary total $^{6}$ opening an inestimable opportunity to identify new substances with therapeutic value. ${ }^{7}$

The genus Lippia comprises approximately 100 species of herbs, shrubs, and small trees, mainly distributed throughout South and Central America with Brazil as a hot spot of diversity. ${ }^{7-9}$ One of the main diversity centers of the genus is located at Espinhaço range, Minas Gerais State, Brazil. ${ }^{10}$ There are many economically important Lippia species and some of them have been used in traditional medicine. The main components identified in the genus include phenolic acids, flavonoids, tannins, saponins, resins, alkaloids, steroids, naphthoquinoids and iridoids. ${ }^{11}$ In spite of several studies about the pharmacological activity of Lippia compounds (e.g. Funari et al. 2012 $2^{12}$ ) and the knowledge that many components - such as those ones listed above- play a role in protecting human cells from UV damage, no reports about the photoprotective activity of Lippia were reported so far.

Considering the wide occurrence of the genus Lippia in Brazil and the use of different species in folk medicine we aimed to investigate the photoprotective activity of four Brazilian Lippia species.

\section{MATERIALS AND METHODS}

\section{Chemicals}

Analytical-grade glycerin (Vetec, Brazil) and ultrapure water $(18.2 \mathrm{M} \Omega \mathrm{cm})$ obtained from an aqua MAX-Ultra
370 Series water purification system (YoungLin, Korea) were used throughout the analysis. Square-shaped (50 x $50 \mathrm{~mm}$ ) polymethylmethacrylate (PMMA) Helioplate ${ }^{\mathrm{TM}}$ HD6 (HelioScreen, France) plates with roughened surface on one side $(\mathrm{Sa} \approx 6 \mu \mathrm{m}$ ) were used as the substrate for the determination of photoprotection activity by diffuse transmittance spectrophotometry.

\section{Equipments}

The in vitro photoprotection experiments were conducted in an UV-2000S Ultraviolet Transmittance Analyzer (Labsphere, USA), composed of two photodiode array spectrographs and equipped with an integrating sphere and a xenon flashlamp. A long-arc xenon Sun test TM insolator, type CPS+ (Atlas, Germany), filtered with its original UV short cut-off filter combined with a Special UV Glass filter (limiting radiation at approximately $290 \mathrm{~nm}$ ), providing a VIS+UVA+UVB spectrum, was used as the artificial UV source for irradiation of the sunscreen samples. PMMA plates were supported firmly throughout the irradiation by a SunTray holder which also provided a dark background behind each plate to reduce the risk of any back exposure.

An electronic analytical balance AY-220 (Shimadzu, Japan) and a positive-displacement manual pipette (Mettler Toledo, USA) were used for the preparation of the samples PMMA plates.

\section{Samples}

Lippia species were collected at the Espinhaço Range, Minas Gerais State, Brazil and transplanted to the Plant Experimental Area at Universidade Federal de Juiz de Fora (UFJF). Dr Fátima Regina Gonçalves Salimena identified the species and the exsiccates were deposited in the 


\begin{tabular}{|lcccc|}
\hline \multicolumn{5}{|c|}{ Table 1: Photoprotection results of Lippia species dried extracts } \\
\hline \multicolumn{1}{|c|}{ Species } & SPF & UVAPF & $\lambda_{\mathrm{c}}$ & UVAVUVB ratio \\
\hline L. brasiliensis & $9 \pm 1.0$ & $8 \pm 0.7$ & 386 & 0.91 \\
\hline L. pseudothea & $6 \pm 1.4$ & $5 \pm 0.5$ & 378 & 0.85 \\
\hline L. rotundifolia & $4 \pm 0.9$ & $3 \pm 0.9$ & 381 & 0.86 \\
\hline L. rubella & $9 \pm 0.7$ & $6 \pm 0.4$ & 375 & 0.77 \\
\hline
\end{tabular}

SPF: Sun Protection Factor; UVAPF:UVA Protection Factor; $\lambda_{c}$ : critical wavelength.

Herbarium Leopoldo Krieger - UFJF, with the respective voucher numbers: 56951 (Lippia brasiliensis), 56941 (Lippia pseudothea), 56946 (Lippia rotundifolia) and 56942 (Lippia rubella).

Specimens' leaves $(50 \mathrm{~g})$ were cleaned with water and dried in a circulating air oven at $21 \pm 2.0^{\circ} \mathrm{C}$ for four days. Subsequently, the material was ground in a knife mill (TA2 , Metvisa, Brazil). The material was macerated in ethanol through static maceration process for three days at room temperature. The ethanol extracts filtrates were subjected to slowly rotary evaporator (R-114-Büchi, Switzerland) under reduced pressure at $40^{\circ} \mathrm{C}$ until the complete removal of the solvent.

The dried extracts were incorporated in a cosmetic neutral lotion at $15 \%$, and then subjected to photoprotection assay.

\section{Photoprotection assay}

The photoprotection assay followed the protocol described by Colipa. ${ }^{13}$ The samples were accurately and quickly weighed (to reduce product evaporation and dryness) to satisfy the application rate of $1.3 \mathrm{mg} \mathrm{cm}^{-2}$ in each PMMA plate (actual quantity applied: $32.5 \mathrm{mg}$, determined by weighing the plates before and immediately after applying the products). They were directly weighed on the plate surface, applied as a large number of small droplets of approximately equal mass, and distributed in an even manner on the roughened surface of the plate. Then, the products were spread over the whole surface with a fingertip covered with a vinyl glove and pre-saturated with the product to prevent possible losses of the amount weighed. For each product, three plates were kept protected from light exposure in a dark chamber at room temperature $\left(\approx 20^{\circ} \mathrm{C}\right)$ for 15 minutes.

After this period, the plates containing the product were placed in the light-path of the transmittance analyzer. The transmission of UV radiation through the sample was measured from 290 to $450 \mathrm{~nm}$ at $1 \mathrm{~nm}$ intervals at 9 different sites of each plate (total measurement area $=2.0$ $\mathrm{cm}^{2}$ ). The blank was prepared using the HD6 plates covered with $15 \mu \mathrm{L}$ of glycerin, because of its non-fluorescence and
UV transparency. For UVAPF, the plates were inserted into the UV irradiation source (temperature maintained below $40^{\circ} \mathrm{C}$ ) and then exposed to a calculated UV dose. After that, new transmission measurements of the sunscreen samples were conducted for acquisition of the second UV spectrum, and then the final UVAPF, the UVA/UVB Ratio and the Critical Wavelength were calculated. Theoretical background can be found in Polonini et al. ${ }^{14}$

The validation of the results was obtained using the Cosmetics Europe Reference Sunscreen S2 (determined $\mathrm{SPF}=18 \pm 1.5, \mathrm{UVAPF}=12 \pm 1.1, \lambda_{\mathrm{c}}=381 \mathrm{~nm}$, and UVA/ UVB Ratio $=0.88$ ). All results were expressed as a mean of 27 determinations (3 plates, 9 readings each, at different sites) for lotions containing $15 \%$ of each dried extract in isolation.

\section{RESULTS AND DISCUSSION}

In the present work, we used the diffuse transmittance in vitro technique to determine the photoprotection profile of four dried extracts of Lippia, because it can determine not only the SPF, but also the protection against UVA radiation (UVAPF), which is important since its role on the skin cancer pathogenesis is currently known. ${ }^{15-17}$ All four species presented considerable protection, both for UVB and UVA radiations, being $L$. brasiliensis the one that presented the higher protection for both parameters (Table 1 and Figure 1). Yet, it is advisable that the UVAPF should be at least $1 / 3$ of the SPF. ${ }^{18}$ and in this case all species meet this criteria.

Moreover, we determined the Critical Wavelength $\left(\lambda_{\mathrm{c}}\right)$, which also measures the UVA protection, being defined as the wavelength at which the integral of the area under the absorption spectrum of the sample reaches $90 \%$ of the total absorption, from 290 to $400 \mathrm{~nm} .{ }^{13}$ The US Food and Drug Administration (FDA ${ }^{19}$ uses this parameter to determine if a product is a broad spectrum sunscreen or not. It considers the broad spectrum test as a pass/ fail test based on the critical wavelength value of $370 \mathrm{~nm}$. Under such classification, all four lotions containing the extracts can be considered broad-spectrum filters. 

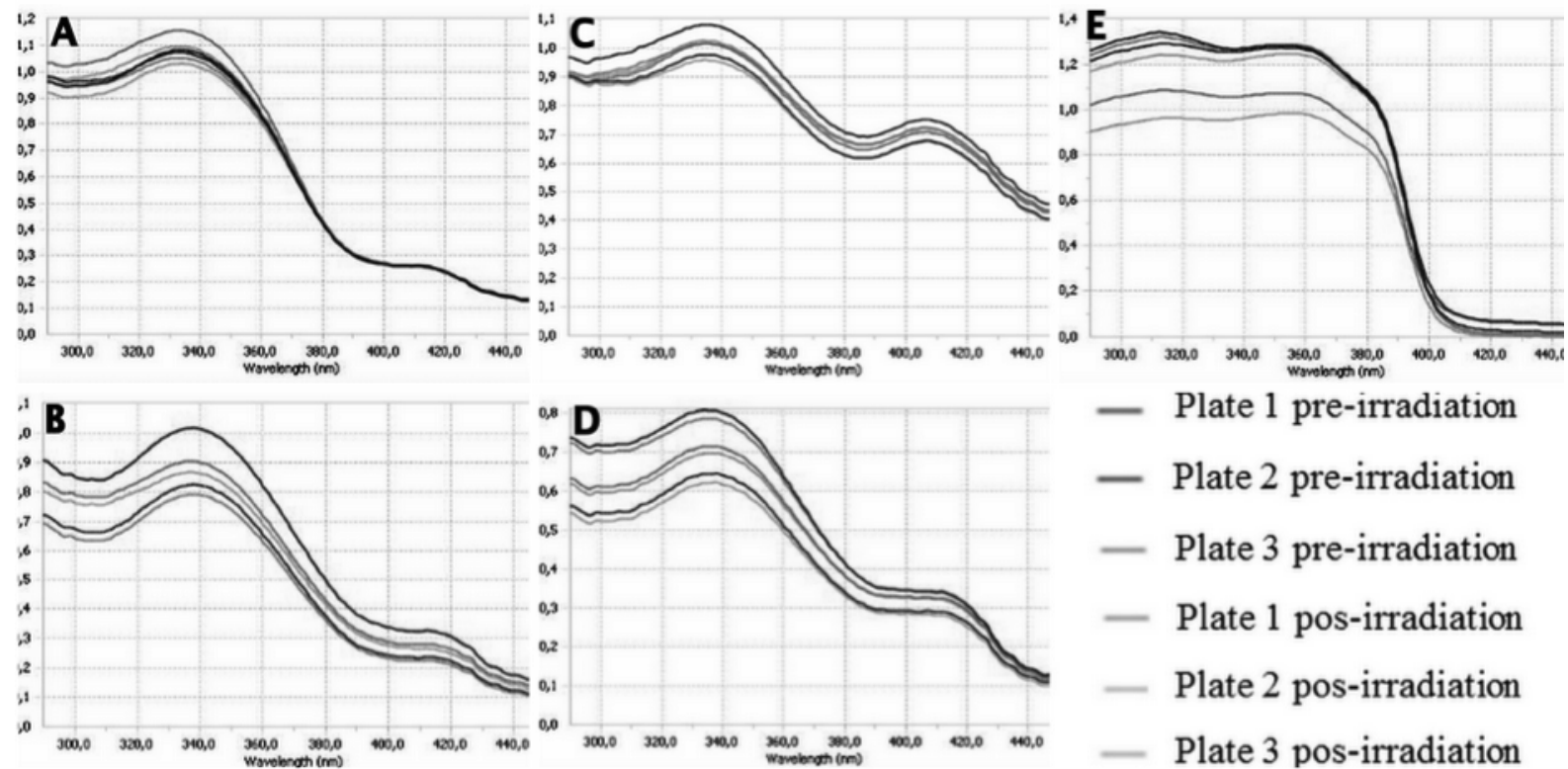

Plate 1 pre-irradiation

Figure 1. UV spectra of lotions containing $15 \%$ of dried extracts of four Lippia species.

A: L. rubella; B: L. pseudothea; C: L. brasiliensis; D: L. rotundifolia; E: Colipa standard. ${ }^{13}$

However, the $\lambda_{c}$ does not take into account the intensity of the whole spectrum, enabling that a filter with less protection present the same value $\lambda c$ of another with superior protection. ${ }^{20-22}$ In this case, the ideal situation regarding the protection in the UVA wavelength region is that it reaches a value similar to SPF protection factor (FPUVA / FPUVB $\approx 1.0$ ). In this study, we have determined the UVA/UVB Ratio, which provides a good idea of which UV region is better blocked by the substances. It is assumed that the closer the Ratio is of the unity, the better the spectrum of protection. In this case, L. brasiliensis showed the best balance between the protection in both regions of solar spectrum (Ratio=0.91).

The UVA/UVB ratio can also be used to provide the socalled Boots Star Rating, ${ }^{23}$ which classifies the products into categories from 0 to 5 stars. Such classification should be done according to initial and post exposure UVA/UVB Ratios. The Boots Star Rating is important to determine the stability of the generated photoprotection values, since the components of the sunscreens may degrade. By this classification, the product containing the dried extracts species are (L. rubella), (L. pseudothea and L. rotundifolia) or (L. brasiliensis).

Finally, under Brazilian law the SPF must be at least $6,{ }^{18}$ for a product to be considered a real sunscreen. In our case, three out of the four species can have an SPF label: L. brasiliensis, L. pseudothea and L. rubella. These results are encouraging, once several studies have been conducted to evaluate the photo protective activity of species of the Brazilian flora, but they do not always succeed. ${ }^{24-27}$

\section{CONCLUSION}

By the exposed, among the four species studied for their use as herbal sunscreens / UV filters, we found that broad spectrum sunscreens were obtained when all of four species were used as single UV filter in the sunscreens formulations, although $L$. brasiliensis presented the best UVA/UVB balance. It was demonstrated that this species generated an estimated in vitro SPF of $9 \pm 1.0$, and an effective UVAPF of $8 \pm 0.7$, at $15 \%$ in a neutral lotion. For UVAPF, this is already the final value that can be put in the final product label. However, for SPF it is still necessary to perform in vivo test in human volunteers, which is highly advisable given the good protection results obtained.

\section{CONFLICTS OF INTEREST}

The authors declare that there is no conflict of interest.

\section{Highlights of Paper}

- our species of Lippia presented sunscreening activity.

- L. brasiliensis presented the best UVA/UVB balance.

- This provide the basis for their use in commercial products. 


\section{Author Profile}

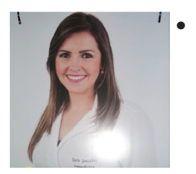

Karla Gonçalves: Is a pharmacist graduated at Federal University of Juiz de Fora. She worked as a researcher at the NUPICS research group, with focus in: analytical chemistry; evaluation of biological potential of Brazilian plant species: and photoprotection. She also worked with pharmaceutical development in pharmaceutical industries. She currently works with compounding pharmacies, focusing in cosmetics products and medical propaganda.

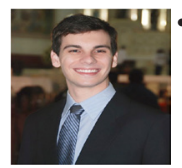

Dr. Hudson Polonini: Is a pharmacist graduated at Federal University of Juiz de Fora. He has MSc and PhD degrees in Health Sciences. His research interests include the delivery of active pharmaceutical ingredients through alternative routes, as well as analytical chemistry for quality control of pharmaceuticals and the development of new health care products with emphasis in sunscreens.

\section{REFERENCES}

1. Angelo G, Lorena C, Marta G, Antonella C. Biochemical composition and antioxidant properties of Lavandula angustifolia Miller essential oil are shielded by propolis against UV radiations. Photochem Photobiol. 2014; 90(3): 702-8.

2. Chanchal D, Swarnlata S. Novel approaches in herbal cosmetics. J CosmDermatol. 2008; 7(2): 89-95.

3. Boligon AA, Pereira RP, Feltrin AC, Machado MM, Janovik V, Rocha JBT, et al. Antioxidant activities of flavonol derivatives from the leaves and stem bark of Scutia buxifolia Reiss. BioresTechnol. 2009; 100(24): 6592-8.

4. Antonelli A, Sanmartín I. Why are there so many plant species in the Neotropics? Taxon. 2001; 60(1): 403-14.

5. De Luca V, Salim V, Atsumi SM, Yu F. Mining the biodiversity of plants: a revolution in the making. Science 2012; 336(6089): 1658-61.

6. Myers N, Mittermeier RA, Mittermeier CG, da Fonseca GAB, Kent J. Biodiversity hotspots for conservation priorities. Nature 2000; 403(6772): 853-8.

7. Salimena FRG. Two new species of Lippia sect. Rhodolippia (Verbenaceae) from South America. Hickenia 2002; 3(32-37): 145-9.

8. Campos JMS, Sousa SM, Silva PS, Pinheiro LC, Sampaio F, Viccini LF. Chromosome numbers and DNA C values in the genus Lippia (Verbenaceae). Plant Syst Evol. 2011; 291(1-2): 133-40.

9. O'Leary N, Denham SS, Salimena F, Múlgura ME. Species delimitation in Lippia section Goniostachyum (Verbenaceae) using the phylogenetic species concept. Bot J Linn Soc. 2012; 170(2): 197-219.

10. Viccini LF, Pierre PMO, Praça MM, Da Costa DCS, Romanel EC, Sousa SM, Peixoto PHP, et al. Chromosome numbers in the genus Lippia (Verbenaceae). Plant Syst Evol. 2006; 256(1-4): 171-8.

11. Pascual ME, Slowing K, Carretero E, Sánchez Mata D, Villar A. Lippia: traditional uses, chemistry and pharmacology: a review. J Ethnopharmacol. 2001; 76(3): 201-14.

12. Funari CS, Gullo FP, Napolitano A, Carneiro RL, Mendes-Giannini MJS, Piacente $S$, et al. Chemical and antifungal investigations of six Lippia species (Verbenaceae) from Brazil. Food Chem. 2012; 135(5): 2086-94.

13. Cosmetics Europe. Method for in vitro determination of UVA protection; 2011.

14. Polonini HC, Lima LL, Gonçalves KM, do Carmo AMR, da Silva AD, Raposo NRB. Photo protective activity of resveratrol analogues. Bioorg Med Chem. 2013; 21(4): 964-8.
15. Polonini HC, Dias RM, Souza IO, Gonçalves KM, Gomes TB, Raposo NR, da Silva AD. Quinolines derivatives as novel sun screening agents. Bioorg Med Chem Lett. 2013; 23(16): 4506-10.

16. Jiang Y, Rabbi M, Kim M, Ke C, Lee W, Clark RL, Mieczkowski PA, Marszalek PE. UVA generates pyrimidine dimers in DNA directly. Biophys J. 2009; 96(3): 1151-8.

17. El Ghissassi F, Baan R, Straif K, Grosse Y, Secretan B, Bouvard $\mathrm{V}$, et al. WHO International Agency for Research on Cancer Monograph Working Group. A review of human carcinogens--part D: radiation. Lancet Oncol. 2009; 10(8): 751-2.

18. Brasil. RDC n. 30. Regulamento Técnico Mercosulsobre Protetores Solaresem Cosméticos. Agência Nacional de Vigilância Sanitária, Brasil; 2012.

19. Food and Drug Administration. 21 CFR Parts 201, 310, and 352. Sunscreen Drug Products for Over-the-Counter Human Use; Final Rules and Proposed Rules. Food and Drug Administration, Silver Spring; 2011.

20. Rai R, Srinivas CR. Photoprotection. Indian J Dermatol Venereol Leprol. 2007; 73(1): 73-9.

21. Diffey BL. Sun screens. Development, evaluation, and regulatory aspects. In: Lowe NJ, Shaath NA, Pathak MA. Marcel Dekker: New York; 1997.

22. Springsteen R, Yurek R, Frazier M, Carr KF. In vitro measurement of sun protection factor of sunscreens by diffuse transmittance. Anal. Chim. Acta.1999; 380(2): 155-64.

23. Boots the Chemist Ltd. The revised guidelines to the practical measurement of UVA/UVB ratios according to the Boots star rating system. The Boots Co. PLC, Notthingham; 2008.

24. Violante IMP, Souza IM, Venturini CL, Ramalho AFS, Santos RAN, Ferrari M. Avaliação in vitro da atividade foto protetora de extratos vegetais do cerrado de Mato Grosso. Braz J Pharmacogn. 2009; 19(2A): 452-7.

25. Souza TM, Santos LE, Moreira RRD, Rangel VLBI. Sun screen activity evaluation of Achillea millefolium L. (Asteraceae). Braz J Pharmacogn. 2005; 15(1): 36-8.

26. Ferrari M, Oliveira MSC, Nakano AD, Rocha-Filho PA. In vitro and in vivo determinations of sun protection factor (SPF) of emulsions with andiroba oil (Carapaguianensis). Braz J Pharmacogn. 2007; 17(4): 626-30.

27. Polonini HC, Gonçalves KM, Gomes TBB, Brandão MAF, Chaves MGAF, Raposo NRB. Amazon native flora oils: in vitro photo protective activity and major fatty acids constituents. Braz J Pharm. 2012; 93(1): 102-8. 